\section{Cold chain and consumers' practices: exploratory results of focus group interviews}

\author{
Stefania Balzan, Luca Fasolato, \\ Barbara Cardazzo, Giulia Berti, \\ Enrico Novelli
}

Dipartimento di Biomedicina Comparata e Alimentazione, Università di Padova, Legnaro (PD), Italy

\begin{abstract}
The aim of this qualitative survey was to gain an insight into the ways consumers purchase, transport and storage fresh and frozen food. In particular, this paper considered consumers' behaviour and the knowledge they have about cold chain. An explorative study was held using focus group interviews (n. 4) as the method for data collection. The sampling group was composed of 24 consumers (4 males and 20 females) and the age ranged from 33 to 78. Data revealed that food safety knowledge is at a fairly good level, however consumer practices in certain cases were inappropriate particularly with respect to transport from the store to home, storage and thaw. Consumers were particularly concerned about frozen food that should not be thawed during shopping or transportation. Knowledge about eggs storage seemed to be dodgy as well. Due to the restricted extent of the sample survey the results cannot be generalized to the whole Italian population; still, this method is particularly useful for discovering not only what people think but why they think that way.
\end{abstract}

\section{Introduction}

Since it is presently impossible for food producers and processors to ensure a pathogen free food supply, the home food preparer plays an essential role to prevent foodborne illnesses. Some authors (Bryan, 1988; Medeiros et al., 2001) reported that only a few types of food handling errors are responsible for the majority of foodborne illness cases. In particular, Medeiros et al. (2001) identified five behavioural topics on which educators and institutions have to concentrate their food safety efforts. The constructs are: i) practice personal hygiene, ii) cook food adequately, iii) avoid cross-contamination, iv) keep food at safe temperatures, and v) avoid food from unsafe sources. It is well known that scarce temperature control during transport and storage is frequently implicated as a cause of foodborne illness (Redmond and Griffith, 2009). The aim of this qualitative survey was to determine consumers' food safety knowledge and practices during purchase, transportation and storage of food. In particular, this paper considered the maintenance and understanding of the cold chain among consumers. Focus group method was used for data collection.

\section{Materials and Methods}

Four focus group interviews were conducted with a total of 24 participants, 4 men and 20 women. The age ranged from 33 to 78 and the contributors lived in the province of Vicenza and Padova (North-Est Italy). Most participants were not familiar with one another. The participants recruited had previously agreed to participate in focus groups if they qualified. The general topic for the discussion, food safety and consumer, was mentioned in this announcement, but the aims of the study were not described. All subjects received a shopper bag and a cold-storage chart. None of participants worked in the food industry and the selection was based on doing regularly food shopping, handling and cooking. The focus groups held were at a private home from October to November 2013. Each interview was conduct from 8.00 to 9.00 p.m., with the exception of the last group interview which was conducted from 4.00 to 5.00 p.m. Coffee and beverages were served to the participants on arrival. After about 10 min the moderator started the discussion by introducing herself and the general subjects for the discussion. The moderator was responsible for simplifying the group discussions and the assistant took notes during the interviews (Brug et al., 1995; Krueger, 1988). Focus groups were audiotaped, and tapes were transcribed literal to ensure systematic analysis of the dialogues. The questions were pre-tested by 6 participants and revised on the basis of results. A semistructured questionnaire was used in the focus groups. Questions were as follows: What do you mean by cold chain? (Q1); Do you ever use an isolated bag to carry your perishable lunch at work or at picnic? (Q2); Do you ever use an isolated bag or cooling box to carry your refrigerated or frozen foodstuffs home? (Q3); During the shopping, at what stage do you purchase fresh (e.g. raw meat, fresh milk, etc.) and frozen food? (Q4); How is important the length of transport of refrigerated or frozen foodstuffs from the time of purchase to your home? (Q5); When do you store fresh or frozen food at home after purchase? (Q6); What do you think about this refrigerator (Figure 1)? Store this food in the refrigerator, please (Figure $2 \mathrm{a})(\mathrm{Q7})$; How do you thaw frozen food? (Q8).

The results were based on available partici-
Correspondence: Stefania Balzan, Dipartimento di Biomedicina Comparata e Alimentazione, Università di Padova, viale dell'Università 16 , 35020 Legnaro (PD), Italy.

Tel. +39.049.8272965 - Fax: +39.049.8278604.

E-mail: stefania.balzan@unipd.it

Key words: Focus group, Domestic hygiene, Consumer behaviour, Food safety education.

Conflict of interests: the authors declare no potential conflict of interests.

Acknowledgements: authors wish to thank the consumers who answered the questions honestly and participated with great enthusiasm.

Received for publication: 8 July 2014 .

Revision received: 23 October 2014.

Accepted for publication: 23 October 2014

This work is licensed under a Creative Commons Attribution 3.0 License (by-nc 3.0).

CC Copyright S. Balzan et al., 2014

Licensee PAGEPress, Italy

Italian Journal of Food Safety 2014; 3:4516

doi:10.4081/ijfs.2014.4516

pants and the number of focus groups was not sufficient to reach a point of saturation (Carlsen and Glenton, 2011).

\section{Results}

As for opinions on cold chain, the majority of respondents (54.2\%) heard the term cold chain but not its significance, and $25 \%$ of consumers knew the term but associated it with several meanings (e.g. freezer, bag or cooling box, frozen food shop, shipping from shop to home) Of respondents, $20.8 \%$ did not knew the term. About Q2, the results showed that almost all of the respondents used a cooling bag only in summer during picnic. At the workplace, perishable foods are left at room temperature until consumption since no refrigerator is available. Lunch was not carried with isolated cooling box with ice freezer blocks.

The choice of place of purchase (farmers market, hypermarket, etc.) depended both on the foodstuffs they wished to purchase and work and family commitments. In relation to the use of isolated bag or cooling box to carry refrigerated or frozen foodstuffs home, the observed data showed that $62.5 \%$ of the respondents used a cooling bag, 20.8\% believed that it was not necessary because they have a short transportation time from shop to home, while $16.7 \%$ of the respondents admitted to forget their bag. Of the participants, $33.3 \%$ did not use ice freezer blocks in 
their cooling bag. Moreover, when cooling bag was used, it was only for storing frozen foods. Few consumers (8.3\%) took frozen food sometimes during their shopping, among them $8.3 \%$ took it as soon as they entered the shop and $83.4 \%$ collected it at the end of their shopping because otherwise thawed. In the case of fresh food, only $20.8 \%$ of respondents took it together frozen at the end of spending and $79.2 \%$ of consumers took raw meat, fresh milk, etc. during their shopping trip. Moreover, respondents reported that sometimes their purchased perishable foods depended on the way they were arranged in stores (in some supermarket the chiller cabinet is near the entrance). All respondents were persuaded that a short transportation time is important for the safety and quality of foodstuffs. At the same time, all participants declared that they quickly put the food in the fridge or in freezer. In particular, they were worried about thawing frozen foods. The consequences of improper handling of frozen foods were mentioned as being of great importance in determining the behaviour of respondents. Figure 1 shows an overstock refrigerator. Looking at Figure 1, 100\% of respondents stated that refrigerator was too full but that it was similar to theirs just after purchasing food at the supermarket. Then, participants were asked if they knew the temperature of their refrigerator in order to establish whether they find storage conditions important (Q7). The majority of the respondents did not know that the fridge has different temperatures (Figure 2b). In particular, they were surprised by the temperatures that can be reached in the door ..soft drinks and milk are always cold! Most participants (95.8\%) stored vegetable and fruit in the drawer (Table 1) and $58.4 \%$ put eggs in the door with or without packaging. Raw fish and meat were stored on the first (25\%) and on the middle shelf (50\%), respectively. Cheese and salami were properly stored in most cases. When we wanted to determine how consumers thaw frozen foods (e.g. raw meat or raw fish), the majority $(70.8 \%)$ of respondents declared to defrost frozen food at room temperature and $29.2 \%$ in the refrigerator. Only in summer some of those who thawed at room temperature put frozen food in the refrigerator. However, some participants declared that sometimes they use the oven to defrost or put frozen food in hot water without protective bag. Only older consumers use the microwave oven to thaw, meanwhile the large part of interviewed said that ..it is dangerous or ..microwave oven makes food soft.

Eggs were mentioned by a number of respondents in different interviews in relation to storage: Why are eggs not in the fridge at the supermarket?, or In the shops you buy them on the shelf but I must put them in the fridge, do I really need too? Participants seemed to be confused by the different storage condition between shop and home.

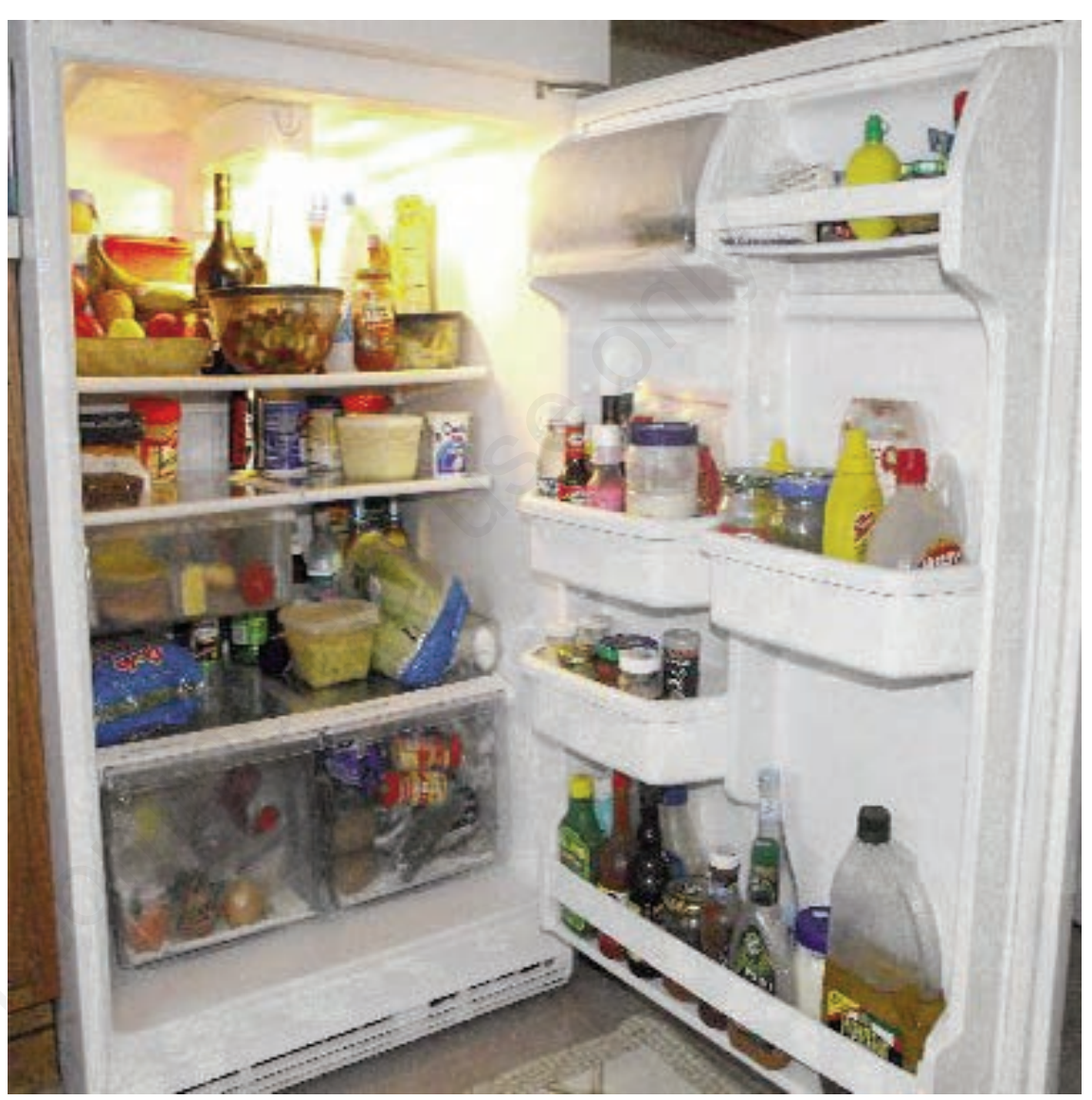

Figure 1. Question 7: What do you think about this refrigerator?

Table 1. Answers to the request Store this food in the refrigerator, please.

\begin{tabular}{|c|c|c|c|c|c|c|}
\hline Foodstuff & $\mathbf{N}$ & $\begin{array}{l}\text { Refrigerator shelf } \\
\text { Top shelf } \\
(1)^{\circ}\end{array}$ & $\begin{array}{l}\text { Middle } \\
\text { shelf } \\
(2)^{\circ}\end{array}$ & $\begin{array}{l}\text { Bottom } \\
\text { shelf } \\
(3)^{\circ}\end{array}$ & $\begin{array}{l}\text { Drawer } \\
(4)^{\circ}\end{array}$ & $\begin{array}{l}\text { Door } \\
(5)^{\circ}\end{array}$ \\
\hline Fresh milk & 24 & 2 & - & - & - & 22 \\
\hline Butter & 24 & 5 & 10 & - & - & 9 \\
\hline Raw meat and raw fish & 24 & 6 & 12 & 5 & 1 & - \\
\hline Salami & 24 & 4 & 13 & 6 & 1 & - \\
\hline Fruits and vegetables & 24 & - & - & 1 & 23 & - \\
\hline Semi hard cheese & 24 & 4 & 13 & 5 & 1 & 1 \\
\hline Eggs & 24 & 2 & 3 & 2 & 1 & 16 \\
\hline
\end{tabular}

\footnotetext{
oSee Figure 2.
} 


\section{Discussion}

Consumers are the final step for food preparation and for prevention of foodborne illnesses (Langiano et al., 2012). Recognition of personal responsibility for food safety is considered to be as a prerequisite for improvement food safety behaviours (Unklesbury et al., 1998). The current study utilized focus groups to gain information about consumers' knowledge on food transport and storage.

Although Redmond and Griffith (2003) suggested that the observation of consumers during handling of food in the home environment is an appropriate method to provide more realistic indication of the food hygiene practices, focus group facilitate the expression of ideas and experiences that might be left underdeveloped in a one-to-one interview. Group data are neither more nor less accurate than data collected by other approaches, but focus groups can be the most suitable method for researching particular types of question (Kitzinger, 1995).

The term cold chain was almost unknown to our respondents. Similar finding were obtained by Ovca and Jevšnik (2009). They reported that consumers frequently associated the term with some categories of food (e.g. icecreams and cold-drinks). Only few of these consumers emphasized the importance of maintaining a cold chain up to the consumer's home. In general, the responsibility of maintaining proper storage condition is delegated to the retailers and other parts of the food chain. Consumers have a significant role to play in food safety, especially in the area of maintaining a cold chain. Results showed that consumers do not pay particular attention to storage of food they bring from home to work or during a picnic. In this respect, some public institutions try to inform consumers about food poisoning due to bad conservation (Van, 2012; Italian Board of Health, 2012).

It is obvious that the potential for temperature abuse would be reduced if consumers acquired refrigerated food at the end of their shopping. Jay et al. (1999) reported that $58.3 \%$ collected raw meat at the end of their shopping, but Jevšnik et al. (2008) stated that only $10 \%$ of respondents did it. We have not measured the time spent in supermarket, but Colwill (1990) reported that the average time was $42 \mathrm{~min}$ and that most people removed food from chilled display within 15 min since their arrival at the store. It is plausible that the temperatures inside the supermarket could reduce the risk of thermal abuse, but it would be desirable that consumers care about even fresh products and not just frozen ones. As previously reported, the purchase practice of perishable foods depended on the way they were arranged in stores. Grocery shopping is an activity that requires time and consumers need to maximize the time especially if they have children or if they work. In the present study the journeys from store to home were completed in 30 min or less and most interviewed made the journey by car, which is consistent with results by Worsfold and Griffith (1997). The use of an isolated bag or cooling box can help to ensure the right temperature of perishable food during transport home. Losasso et al. (2012) noted that 14 and $25 \%$ of respondents used cool shoppers to transport home refrigerated and frozen products, respectively. In our study it is interesting to note that this behaviour was a

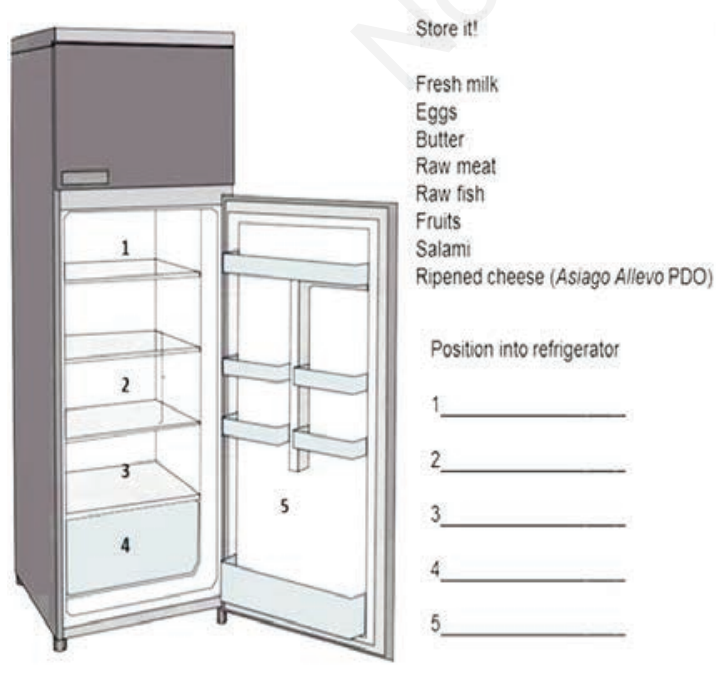

b

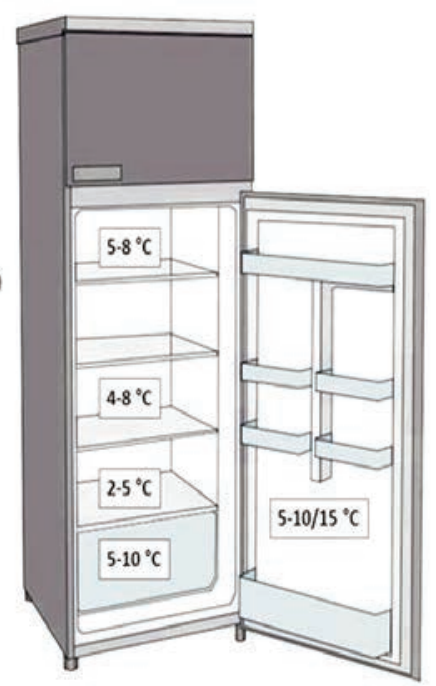

Figure 2. Test of proper food storage in the refrigerator (a) and temperature (b).

obvious for older people who participated in the focus group. Others consumers seemingly thought that to be quick was enough to preserve food. Our results reveal that respondents do not know the temperature of their refrigerator or they do not read the instructions provided by the producers on the most modern refrigerators. Raw fish and meat are store especially on top and middle shelf because consumers do not know the coldest location of refrigerator. Terpstra et al. (2005) reported that consumers showed that they pay great attention when it comes to storing meat, as it is considered as a risky product due to its perishability.

This evidence partially agrees with our study. The same research reported that in two thirds of the cases the temperature of the refrigerators was higher than $7^{\circ} \mathrm{C}$. Ovca and Jevšnik (2009) reported that the majority of respondents stores fresh meat on the top shelf of a refrigerator, but the large part of their consumers buy meat for daily use which decreases the risk of cross-contamination and bad conservation. The same authors noted that respondents associate the arrangement of food more with space availability rather than the need to follow food hygienic procedures. For our respondents too choosing where foods have to be placed is based on practical consideration; it is plausible that the middle shelf is more convenient and accessible than the other ones. Health authority (Italian Board of Health, 2013; FDA, 2013) gives simply advices also on proper food storage (avoid overpacking, keep food cover and avoid drip, clean the fridge out frequently and, check expiration dates), but these indications are possibly not read. As far as thawing is concerned, consumers seemed to follow the instructions reported on the label (e.g. vegetable soup, pizza, French fries, etc.). However, when they thawed homemade frozen foods product (e.g. raw meat), some critical issues were found. Consumers tended to consider as safe frozen products and thawing seemed to affect only the organoleptic characteristics. This behaviour could lead to health risks, particularly when meat or fish are defrosted at rather less suitable places and are inadequately prepared (Damen and Steenbekkers, 2007). Langiano et al. (2012) reported that defrosting of meat and fish at room temperature was very common compared to defrosting in the refrigerator. Also Jevšnik et al. (2008) reported that the majority of the respondents thawed meat improperly.

Redmond and Griffith (2004) advise that judgments of optimistic bias and the illusion of control concerning food safety during domestic food preparation are prevalent among consumers. This misconception of consumers may contribute to continue implementation of unsafe food-handling behaviours during domestic food preparation. 
results of focus group interviews. Food Qual Prefer 6:99-107.

Bryan FL, 1988. Risks of practices, procedures and processes that lead to outbreaks of foodborne diseases. J Food Protect 51:66373.

survey, the findings are considered as exploratory research and the results cannot be generalized to the whole Italian population. However, the results are consistent with the literature. Findings showed some gap in respect of domestic cold chain. The attitudes of consumers towards food safety and their practices at home should be points of interest to food producers and retailers, public authorities and health educators.

There was a higher risk for food handling errors in families with children, older persons and pregnant women. It is unthinkable that food safety behaviour at home is like that of a food industry, but it is necessary to inform consumers about the risks due to improper handling practice. Food safety messages should focus on the different members of a population with adequate communication methods. Food hygiene principles could be transmitted to children (and to their parents) by properly educated teachers. Correct practices concerning food handling and storage could possibly be diffused also during cooking television programmes, in cooking magazines or recipe books. Also, an informal (but correct) education could lead consumers to think in terms of behavioural changes. Safety-conscious consumers are stronger partners within food safety culture.

\section{References}

Brug J, Debie S, van Assema P, Weijts W, 1995. Psychosocial determinants of fruit and vegetable consumption among adults:
Carlsen B, Glenton C, 2011. What about N? A methodological study of sample size reporting in focus group studies. BMC Med Res Methodol 11:26.

Colwill JS, 1990. Survey of shopping habits for chilled foods. Campden Food and Drink Research Association ed., Chipping Campden, UK.

Damen FWM, Steenbekkers LPA, 2007. Consumer behaviour and knowledge related to freezing and defrosting meat at home. An exploratory study. Brit Food J 109:511-8.

FDA, 2013. Refrigerator thermometers: cold facts about food safety. Available from: http://www.fda.gov/Food/ResourcesForYou/ Consumers/ucm253954.htm

Italian Board of Health, 2012. Decalogo alimentazione estate 2012. Available from: http:/www.salute.gov.it/imgs/C_17_opusc oliPoster_147_allegato.pdf

Italian Board of Health, 2013. Il mio frigo. Available from: http://www.salute.gov.it /portale/news/p3_2_3_1_1.jsp?lingua=ital iano\&menu $=$ dossier $\& p=$ dadossier \&id $=8$

Jay LS, Comar D, Govenlock LD, 1999. A national Australian food safety telephone survey. J Food Protect 62:921-8.

Jevšnik M, Hlebec V, Raspor P, 2008. Consumers' awareness of food safety from shopping to eating. Food Control 19:73745.

Kitzinger J, 1995. Introducing focus groups. Brit Med J 311:299-302.

Krueger RA, 1988. Focus groups; a practical guide for applied research. Sage Publ.,
Newbury Park, UK.

Langiano E, Ferrara M, Lanni L, Viscardi V, Abbatecola AM, De Vito E, 2012. Food safety at home: knowledge and practices of consumers. Public Health 20:47-57.

Losasso C, Cibin V, Cappa V, Roccato A, Vanzo A, Andrighetto I, Ricci A, 2012. Food safety and nutrition: improving consumer behaviour. Food Control 26:252-8.

Medeiros L, Hillers V, Kendall P, Mason A, 2001. Evaluation of food safety education for consumers. J Nutr Educ 33:27-34.

Ovca A, Jevšnik M, 2009. Maintaining a cold chain from purchase to the home and at home: consumer opinions. Food Control 20:167-72.

Redmond EC, Griffith CJ, 2003. Consumer food handling in the home: a review of food safety studies. J Food Protect 66:130-61.

Redmond EC, Griffith CJ, 2004. Consumer perceptions of food safety risk, control and responsibility. Appetite 43:309-13.

Redmond EC, Griffith JC, 2009. The importance of hygiene in the domestic kitchen: implications for preparation and storage of food and infant formula. Perspect Public Heal 129:69-76.

Terpstra MJ, Steenbekkers LPA, de Maertelaere NCM, Nijhuis S, 2005. Food storage and disposal: consumer practices and knowledge. Brit Food J 107:526-33.

Unklesbury N, Sneed J, Toma R, 1998. College students attitudes, practices and knowledge of food safety. J Food Protect 61:117580.

Van D 2012. Perfect food safe picnics! Available from: http://www.foodsafety.gov/blog/perfectfood.html

Worsfold D, Griffith C, 1997. Food safety behaviour in the home. Brit Food J 99:97-104. 